\title{
Scope of microcalorimetry in the area of macrocyclic chemistry
}

\author{
Magnus Stödeman and Ingemar Wadsö \\ Division of Thermochemistry, Chemical Center, Lund University \\ P O Box 124, S-221 00 Lund, Sweden
}

\begin{abstract}
A brief introduction to solution thermodynamics and microcalorimetric techniques is given. The areas of titration and dissolution microcalorimetry applied to the studies of macrocyclic ligand binding processes are discussed. As an illustration, the results of a microcalorimetric study involving the binding of a series of alkane-1-ols to $\alpha$-cyclodextrin are reviewed and discussed.
\end{abstract}

\section{Introduction}

Calorimeters are instruments used for the direct measurement of heat quantities, heat production rates and heat capacities. Different measurement principles are employed and a very large number of practical designs have been reported. A calorimeter is a thermodynamic instrument but can also be employed as an analytical tool, for example as a 'process monitor'. With respect to the narrow field of macrocyclic chemistry, one may, in particular, point at three important areas for isothermal calorimetric experiments: (i) investigations of the thermodynamic properties of host - guest complex formation; (ii) thermodynamic characterization of macrocyclic compounds with respect to their intermolecular interactions in the condensed state and in solutions, (iii) characterization of the effect of interactions between living cellular systems and macrocyclic compounds and complexes. So far no studies seem to be reported in the latter field, (iii), but the area is judged to be important, not the least in connection with the use of macrocyclic compounds as drug carriers.

About 100 calorimetric investigations involving macrocyclic compounds have been reported, most of them on cyclodextrins, see for example (1 - 5). For recent work on crown ethers, see $(6,7)$. Few calorimetric investigations have so far been conducted on cryptands, $(1,7)$ and calixarenes $(8)$.

In the present paper, the term 'isothermal microcalorimeter' is used for particularly sensitive calorimeters, which are used in experiments where the temperature stays essentially constant. The sensitivity for such instruments is typically $1 \mu \mathrm{W}$ or better, and the amount of material employed in a chemical experiment usually is less than $1 \mu \mathrm{mol}$.

Modern microcalorimetry has much extended the use of calorimetry in studies of ligand binding, dissolution, heat capacity (small samples, dilute solutions) and in experiments with living cells. With respect to dissolution measurements and in work with living materials it is often essential that the calorimeters not only have a high sensitivity but also that the instruments allow very long measurement periods (days). Fortunately, several modern microcalorimeters have an excellent baseline stability making them well suited for such work $(9,10)$.

\section{Calorimetric determination of some thermodynamic properties}

This paper will concentrate on calorimetric techniques applied in thermodynamic experiments. However, even for cases where calorimeters mainly are employed as analytical instruments, it is important to express results in terms of well defined thermodynamic properties. Below we briefly review some thermodynamic properties which can be determined calorimetrically and are of particular importance for the area treated here. 
When a 'heat of reaction' is measured under conditions of constant pressure (in practice usually the atmospheric pressure) it is the enthalpy change, $\Delta H$, that is determined. The heat production rate, often called the 'thermal power', $P$, or heat flow, $\phi$, is a thermodynamic as well as a kinetic property which typically is determined in experiments where the calorimeter is used as a process monitor,

$$
P=\mathrm{d}(\Delta H) / \mathrm{dt}
$$

Enthalpy measurements conducted for a process at different temperatures will lead to the change in heat capacity for the system at constant pressure, $\Delta C_{\mathrm{p}}$.

$$
\Delta C_{\mathrm{p}}=\mathrm{d}(\Delta H) / \mathrm{d} T
$$

This property has proved to be of major importance in, for example, studies of binding processes conducted in aqueous solution. However, surprisingly few such measurements have been reported in the area of macrocyclic chemistry.

Dissolution calorimetry is of particular importance in studies of intermolecular forces in pure compounds and of solute - solvent interactions. Such measurements are therefore also important for investigations of binding reactions in solution as the thermodynamics of such processes to a large extent is governed by the solvation of the reaction components. From a comparison of enthalpy values for dissolution of a compound into two different solvents $\left(\Delta_{\text {sol }} H_{1}\right.$ and $\left.\Delta_{\text {sol }} H_{2}\right)$ the enthalpy of transfer $\left(\Delta_{\text {trans }} H\right)$ of the compound between the two solvents can be derived,

$$
\Delta_{\text {trans }} H=\Delta_{\text {sol }} H_{1}-\Delta_{\text {sol }} H_{2}
$$

It should be noted that the properties $\Delta_{\text {trans }} H$ and $\Delta_{\text {trans }} C_{\mathrm{p}}$ reflect changes in the interactions between the solute and the solvent, without any contribution from the intermolecular forces present in the pure compounds used in the determination of the $\Delta_{\text {sol }} H$-values.

A special case of $\Delta_{\text {trans }} H$ is the enthalpy of transfer of a compound from the gasphase to solution, usually called the enthalpy of solvation, $\Delta_{\mathrm{sol}} H$. For solids and liquids this property is obtained as the difference between values for enthalpy of dissolution and enthalpy of vaporization (sublimation), $\Delta_{\mathrm{vap}} H$.

$$
\Delta_{\text {solv }} H=\Delta_{\text {sor }} H-\Delta_{\text {vap }} H
$$

Except for very dilute solutions, there can be significant interactions between solute molecules in a solution. It is therefore often desirable to determine values for enthalpies of dilution which may allow calculation of $\Delta_{\text {sol }} H$-values at infinite dilute solutions, $\Delta_{\text {sol }} H^{\infty}\left(\Delta_{\text {trans }} H^{\infty}, \Delta_{\text {sol }} C_{\mathrm{p}}^{\infty}\right)$. When microcalorimetric techniques are used, it is frequently possible to work in concentration ranges which are low enough to be considered as infinitely dilute. The partial molar heat capacity for a solute (A) at infinite dilution, $C_{\mathrm{p}}^{\infty}(\mathrm{A})$, is not influenced by any intermolecular forces except by those between solute and solvent. This property can be derived from the heat capacity value determined for the pure solute $\left(^{*}\right)$ and the dissolution heat capacity value

$$
C_{\mathrm{p}}^{\infty}(\mathrm{A})=\Delta_{\mathrm{sol}} C_{\mathrm{p}, \mathrm{m}}^{\infty}(\mathrm{A})+C_{\mathrm{p}, \mathrm{m}}^{*}(\mathrm{~A})
$$

where index $\mathrm{m}$ indicates 'molar'.

Alternatively, $C_{\mathrm{p}}^{\infty}$ (A) may be determined by direct heat capacity measurements of very dilute solutions. From a practical point of view, the most important thermodynamic property for a binding process is the concentration equilibrium constant, $K_{\mathrm{c}}$, where index c indicates that the $K$-value is based on equilibrium concentrations rather than activities (which in most cases not are available). For many binding processes it is possible to determine $K_{0}$ values and corresponding enthalpy values simultaneously by use of titration calorimeters or flow mixing calorimeters, $c f$ below. The relationship between equilibrium constant, standard Gibbs energy change $\left(\Delta G^{\circ}\right)$ and corresponding entropy change $\left(\Delta S^{\circ}\right)$ are given by

$$
\begin{aligned}
& \Delta G^{\circ}=-\mathrm{RT} \ln K_{\mathrm{c}} \\
& \Delta G^{\circ}=\Delta H^{\circ}-T \Delta S^{\circ}
\end{aligned}
$$

where $\mathrm{R}$ is the gas constant and $\mathrm{T}$ the absolute temperature. 


\section{Microcalorimetric techniques}

The design and properties of microcalorimeters which are of interest in the present context have been discussed in some detail elsewhere $(9,10)$. The treatment here will therefore be limited to a few basic concepts.

\section{Calorimetric principles}

A large number of different calorimeters, some of which may be called microcalorimeters, have been designed for use in chemistry and in biology. Sometimes a rather confusing terminology is used but from the point of view of heat measurement principles such calorimeters are of three main types: adiabatic, heat conduction (or heat flow) and power compensation calorimeters.

Adiabatic calorimeters. In an ideal adiabatic calorimeter there is no heat exchange between the calorimetric vessel and the surroundings. The heat quantity evolved during an experiment, $Q$, is equal to the product between the measured temperature change and the heat capacity of the vessel and its content. A 'practical' heat capacity value, the calibration constant $\varepsilon_{\mathrm{a}}$, is determined experimentally. Semi-adiabatic instruments, sometimes called 'isoperibolic' calorimeters, are often used. For such instruments, the heat exchange with the surroundings is significant and a corrected value for the temperature change should be used.

Heat conduction calorimeters. The heat evolved in the reaction vessel of a heat conduction calorimeter is allowed to flow to a surrounding 'heat sink', usually a metal block. The heat flow is recorded, normally by letting it pass through a thermopile wall. In practice this wall usually consists of one or more semiconducting thermocouple plates positioned between the calorimetric vessel and the heat sink. At steady state the heat flow is directly proportional to the thermopile potential, $U$. The thermal power, $P=\mathrm{d} Q / \mathrm{d} t$, is then

$$
P=\varepsilon_{\mathrm{c}} U
$$

where $\varepsilon_{\mathrm{c}}$ is a calibration constant. Ideally $\varepsilon_{\mathrm{c}}$ is equal to the quotient between the average heat conductance of the thermocouples forming the thermopile and the Seebeck coefficient for the thermocouple material, $c f$ (11).

The heat quantity evolved during a time $\Delta t$ is thus

$$
Q=\varepsilon_{\mathrm{c}} U \Delta t
$$

For a non-steady-state process, the relationship between the thermopile potential and the thermal power of the process is, ideally, given by Tian's eqn.

$$
P=\varepsilon_{\mathrm{c}}(U+\tau \mathrm{d} U / \mathrm{d} t)
$$

where $\tau$ is the time constant for the instrument. In practice, it is sometimes necessary to use an expression with more than one time constant (12). Integration of eqn (10) will give

$$
Q=\varepsilon_{\mathrm{c}} \int_{\mathfrak{t}_{1}}^{t_{2}} U \mathrm{~d} t
$$

provided that the initial and the final potential are identical (ideally $=0$ ).

Most isothermal microcalorimeters currently used in solution chemistry and in biology are of the heat conduction type.

Power compensation calorimeters. When an adiabatic calorimeter is used to monitor an exothermic process, there will be a temperature increase in the reaction vessel which stays constant when the process has gone to completion. In a heat conduction calorimeter the process will cause a temporary temperature increase, but when the reaction has finished, the temperature will return very close to its initial value. In both cases it is possible to compensate for the temperature increase by applying a cooling power to the reaction vessel. This is most conveniently achieved by use of Peltier effect cooling: when an electrical current, $I$, is allowed to pass through a thermopile plate, there will be a cooling power on one side of the plate, $-P$, and corresponding heating power on the other side.

$$
-P=\pi I-r I^{2}
$$

where $\pi$ is a material constant and $r$ is an 'effective' resistance value for the thermopile. The thermal power of the process is, ideally, equal to $P$ provided that the temperature of the reaction is kept constant. For an endothermic process, power compensation can be made by reversing the current through the 'cooling thermopile' or by use of an electrical heater. 


\section{Titration microcalorimetry and ligand binding processes}

Microcalorimetric binding studies involving macrocyclic compounds are in most cases conducted by batch titration techniques $(10,13-15)$. A thermostated solution of one of the reaction components is injected stepwise into a solution of the other component which is contained in the calorimetric vessel. Some (macro)calorimeters are also suitable for continuous titration (continuous injection) experiments (16) Flow microcalorimeters can be used in stepwise 'titration experiments' where each titration point is obtained by mixing two solutions in a flow mixing vessel, see for example $(9,10,17)$.

By titration calorimetry it is often possible to determine, simultaneously, the equilibrium constant and corresponding enthalpy and entropy values for a binding reaction, $c f$ eqns (6), (7). The interpretation of the experimental results is based on the assumption that heat quantities evolved, corrected for dilution effects, are proportional to the amount of titrant reacted. If the equilibrium constant is very large, the titrant will be almost quantitatively consumed until the equivalent point has been reached (batch experiment). Such measurements will directly lead to values for the enthalpy change and will also provide information about the stoichiometry of the process. However, no value can be derived for $K_{\mathrm{c}}$. For processes with moderately high $K_{\mathrm{c}}$-values, an increasingly large fraction of the titrant will not be consumed as the experiment proceeds. The fraction of non-reacted titrant obviously reflects the value of the equilibrium constant. In order to derive values for the thermodynamic quantities, it is first necessary to predict a molecular model for the reaction measured, for example a simple $1: 1$ binding reaction:

$$
\mathrm{A}+\mathrm{B}=\mathrm{AB}
$$

However, it is common for macrocyclic compounds to be involved in more complex reaction scheemes like

$$
\begin{aligned}
& A+B=A B \\
& A+A B=A_{2} B
\end{aligned}
$$

or

$$
\begin{aligned}
& A+B=A B \\
& A B+B=A B_{2}
\end{aligned}
$$

Calculation procedures. Calorimetric raw data are fitted to an assumed model

$$
\begin{aligned}
& \mathrm{A}+\mathrm{jB}=\mathrm{AB}_{\mathrm{j}} \\
& K_{\mathrm{c}, \mathrm{j}}=\frac{\left[\mathrm{AB}_{\mathrm{j}}\right]}{[\mathrm{A}][\mathrm{B}]^{\mathrm{j}}}
\end{aligned}
$$

where $[A],[B]$ and $\left[A B_{j}\right]$ are the concentrations of the free reactants $A$ and $B$, and of the formed complex $\mathrm{AB}_{\mathrm{j}}$, respectively. The fitting parameters are the concentration equilibrium constant $K_{\mathrm{c}, \mathrm{j}}$, and the

corresponding enthalpy change $\Delta H_{j}^{\circ}$, for the binding step $\mathrm{j}, \mathrm{j}=\{1,2, .$.$\} . Optimal experimental conditions$ (concentrations of reactants) during a calorimetric experiment are best obtained by performing computer simulations prior to the calorimetric series of measurements. Values for the fitting parameters $\left(K_{\mathrm{o}, 1}, K_{\mathrm{c}, 2}\right.$,

$\left.\ldots \Delta H_{1}^{\circ}, \Delta H_{2}^{\circ} \ldots\right)$ for the model chosen are then assumed, often using results from a preliminary calorimetric experiment. Enthalpy of dilution of reactants are often significant and must then be corrected

for. Values for $K_{\mathrm{c}, \mathrm{j}}$ and $\Delta H_{\mathrm{j}}^{\circ}$ are then normally obtained by an iterative non-linear regression procedure $(14,15,18-21)$. The statistical treatment of the experimental results is of crucial importance for the quality of the thermodynamic data derived, $c f$ Hallen (20). Commercial instruments are now normally delivered with computer programs for the calculation of $K_{\mathrm{c}}$ - and $\Delta H^{\circ}$-values according to different binding models.

Small and random least square residuals are obtained as a result of the minimization calculations when a correct model has been used. Such results will thus support the assumed model but will not prove it. For reaction systems indicated by eqns (14) and (15), it is usually not possible to obtain accurate values for all

four constants $\left(K_{\mathrm{c}, 1}, K_{\mathrm{c}, 2}, \Delta H_{1}^{\circ}\right.$ and $\left.\Delta H_{2}^{\circ}\right)$. It is therefore felt that for binding reactions more complex than $1: 1$ equilibria it is very desirable to support the binding model and the $K_{0}$-values by more specific measurements than calorimetry. However, one of the great features with calorimetry is that it can be applied on all kinds of processes - for many equilibria there is no suitable specific analytical method available. 
van't Hoff measurements. Even for the determination of $K_{\mathrm{c}}$ for a simple $1: 1$ binding reaction a non-calorimetric analytical technique might give a more accurate $K_{\mathrm{c}}$-value, for example if the $\Delta H$-value is close to zero. Why then use calorimetry at all in a thermodynamic investigation of a binding process for which suitable specific analytical methods are available? Why not determine $K_{\mathrm{c}}$ at different temperatures and evaluate $\Delta H^{\circ}$ by the van't Hoff equation?

$$
\frac{\mathrm{d} \ln K}{\mathrm{~d}(1 / \mathrm{T})}=\frac{\Delta H^{\circ}}{R}
$$

The answer is that a very high accuracy over a wide temperature range is needed in the determination of $K_{\mathrm{c}}$. Otherwise the propagation of error in $K_{\mathrm{c}}$ to those in $\Delta H^{\circ}$ and $\Delta S^{\circ}$ and, in particular, in $\Delta C_{\mathrm{p}}^{\circ}$, will make these latter values almost useless. Table (1) shows some results from an error analysis made by King (22). It is seen that values determined for $\log K$ with an accuracy which by normal standard is considered good $( \pm 0.02)$ will lead to $\Delta C_{p}^{\circ}$-values which are quite poor to useless. However, if $\log K$ is determined with an accuracy of \pm 0.001 (which, normally, cannot be attained), at many temperatures over a wide temperature range, the errors in $\Delta H^{\circ}\left(\Delta S^{\circ}\right)$ and $\Delta C_{p}^{\circ}$, will be on the same level as those obtained in a first class calorimetric equilibrium study.

Table 1. Determination of values for $\Delta H^{\circ}$ and $\Delta C_{\mathrm{p}}^{\circ}$ from equilibrium measurements at different temperatures. Propagation of errors in $\log K$ for a 1:1 binding reaction to errors in $\Delta H^{\circ}$ and $\Delta C_{\mathrm{p}}^{\circ}$ at $25^{\circ} \mathrm{C}( \pm \mathrm{SD})$. From King (22).

\begin{tabular}{|l|c|c|c|}
\hline$\pm \mathrm{SD}$ in $\log K$ & $\begin{array}{c}\text { Experimental } \\
\text { temperatures } /{ }^{\circ} \mathrm{C}\end{array}$ & $\begin{array}{c} \pm \mathrm{SD} \text { in } \\
\Delta H^{\circ} / \mathrm{kJ} \cdot \mathrm{mol}^{-1}\end{array}$ & $\begin{array}{c} \pm \mathrm{SD} \text { in } \\
\Delta C_{\mathrm{p}}^{\circ} / \mathrm{J} \cdot \mathrm{K}^{-1} \cdot \mathrm{mol}^{-1}\end{array}$ \\
\hline 0.02 & $20,22,24,26,28,30$ & 4 & 2800 \\
\hline 0.02 & $\begin{array}{c}5,10,15,20,25,30, \\
35,40,45,50\end{array}$ & 0.8 & 120 \\
\hline 0.001 & 0.04 & 6 \\
\hline
\end{tabular}

Displacement titration. It is in practice not possible to determine by microcalorimetry $K_{\mathrm{c}}$ values higher than about $10^{7}$ (for a $1: 1$ binding reaction), $c f(20)$. However, using the technique of 'displacement titration', it is possible to arrange for experimental conditions where the fraction of non-reacted titrand will be significant even when very strong complexes are investigated:

$$
\begin{array}{lll}
\mathrm{A}+\mathrm{B}=\mathrm{AB} & K_{\mathrm{c}, 1}, & \Delta H_{1}^{\circ} \\
\mathrm{AB}+\mathrm{C}=\mathrm{AC}+\mathrm{B} & K_{\mathrm{c}, 2}, & \Delta H_{2}^{\circ} \\
\mathrm{A}+\mathrm{C}=\mathrm{AC} & K_{\mathrm{c}, 3}, & \Delta H_{3}^{\circ} \\
K_{\mathrm{c}, 3}=K_{\mathrm{c}, 1} \cdot K_{\mathrm{c}, 2} & & \\
\Delta H_{3}^{\circ}=\Delta H_{1}^{\circ}+\Delta H_{2}^{\circ} &
\end{array}
$$

Assume that $K_{\mathrm{c}, 3}$ (eqn (21)) is too high to measure directly by titration calorimetry. One may then titrate compound $\mathrm{C}$ with a complex $\mathrm{AB}$ eqn (20) for which the binding constant is known or can be determined. For recent examples where this technique is applied in microcalorimetry, see e.g. $(7,23)$. 


\section{Dissolution calorimetry}

Thermodynamic values for a macrocyclic ligand binding reaction can be very different depending on the solvent as shown by the examples given in Table 2 .

Table 2. Thermodynamic values for the binding of $m$ (p-Hydroxyphenyl azo)benzoate anion to $\alpha$-cyclodextrin in water and in N, N,-Dimethylformamide (DMF) at $25^{\circ} \mathrm{C}$. From Danil de Namor et al (24).

\begin{tabular}{|l|c|c|c|}
\hline Solvent & $\frac{\Delta G^{\circ}}{\mathrm{kJ} \cdot \mathrm{mol}^{-1}}$ & $\frac{\Delta H^{\circ}}{\mathrm{kJ} \cdot \mathrm{mol}^{-1}}$ & $\frac{\Delta S^{\circ}}{\mathrm{J} \cdot \mathrm{K}^{-1} \cdot \mathrm{mol}^{-1}}$ \\
\hline Water & -21.2 & -33.4 & -41 \\
\hline DMF & -19.8 & -21.4 & -5 \\
\hline
\end{tabular}

When a macrocyclic compound takes part in a ligand binding process in solution it is likely that solvent molecules, originally bound to the macrocyclic cavity, partly or completely will be replaced by the guest molecule. As suggested by the examples given in Table 2, such displacement processes can give very large contributions to the overall thermodynamic changes accompanying the binding process. Enthalpy changes for the binding of solvent molecules can be investigated by vaporization calorimetry provided that the macrocyclic compound has a non-significant vapour pressure. Alternatively, the enthalpy of binding of solvent molecules can be investigated calorimetrically by dissolution of macrocyclic compounds with and without bound solvent molecules.

It is often useful to consider properties of simple models when results from thermodynamic investigations of macrocyclic ligand binding processes are analyzed. For example, the binding reaction can be seen as a simple transfer process where the solvated guest molecule shifts environment to that provided by the binding site in the macrocyclic compound. The model can be further simplified by substituting the binding site with a suitable solvent which will give the guest molecule an environment, which to some degree will resemble that of the assumed binding site. Such models can be varied systematically using different solvents and different guest molecules. As was discussed earlier, transfer enthalpies and heat capacities can be determined by dissolution measurements, eqn (3).

Micro dissolution calorimetry is now well developed $(10,25)$. Instruments and working procedures have been reported for dissolution of easily or slightly soluble liquids $(26)$, for slightly soluble gases $(27,28)$ and for solids $(29-31)$. The instruments developed in our laboratory $(26,28,29,31)$ form parts of a modular system of titration - perfusion microcalorimeters $(10,32)$ where the solvent flows through the vessel. In one of the instruments for solid solutes (29), the (slightly soluble) solute initially is in contact with a saturated solution whereas in the other instrument (31) the solid material (easily or slightly soluble) is initially dry. The enthalpy of dissolution as measured by these two instruments can thus be different, in particular if a macrocyclic compound is studied (where in the first case the cavity presumably will be filled with solvent molecules).

Murphy and Gill have reported an interesting dissolution method for slightly soluble solids using a titration calorimeter (30).

For easily soluble liquid and solid solutes it is sometimes suitable to use macrocalorimetric techniques for dissolution measurements which may lead to more accurate results. New developments in macro solution calorimetry (dissolution, reaction) significantly have narrowed the sensitivity gap between micro and macro techniques (Thermometric's 2225 Precision Solution Calorimeter).

\section{A case study}

At this point it may be instructive to discuss results from a microcalorimetric study (33) involving the binding of a series of simple guest molecules (straight-chain alkane-1-ols, $\mathrm{ROH}$ ) to a macrocyclic compound ( $\alpha$-cyclodextrin, $\alpha-C D$ ). Fig. 1 a summarizes results from a stepwise microcalorimetric titration experiment where an aqueous solution of hexan-1-ol stepwise was injected into an aqueous solution of $\alpha-C D$ at $298.15 \mathrm{~K}$. The points show the heat quantities determined experimentally, $\mathrm{Q}$, plotted 
against the injection number, $\mathrm{N}$. A curve calculated by use of values derived for $K_{\mathrm{c}}$ and $\Delta H^{\circ}$, assuming a $1: 1$ binding model, eqn (24), is also shown

$$
\mathrm{ROH}+\alpha-\mathrm{CD}=\alpha-\mathrm{CD} \cdot \mathrm{ROH}
$$

A good agreement is found between the experimental points and the curve supporting the assumed binding model. But the agreement does not prove that the assumed model is correct! For the lower alcohols $\left(\mathrm{C}_{3}\right.$ $\mathrm{C}_{5}$ ) similar agreements were found.

For heptan-1-ol as guest molecule, the picture looks quite different, Fig. 1 b. A clear systematic deviation is seen between the experimental points and the curve which again was based on the assumption of the simple $1: 1$ binding model, eqn (24). However, the agreement between the experimental points and the curve become satisfactory if the calculations were based on a model where $1: 1$ as well as $1: 2$ complexes are formed, Fig $1 \mathrm{c}$. Due to the low solubility of heptan-1-ol in water, it was not possible to vary the $\mathrm{ROH}: \alpha-\mathrm{CD}$ ratio as much as desirable and the values obtained for the second complex were uncertain. Therefore, its composition ( $\mathrm{ROH} \cdot[\alpha-\mathrm{CD}]_{2}$ or $[\mathrm{ROH}]_{2} \cdot \alpha-\mathrm{CD}$ ) could not be identified from a statistical point of view. However, from results of other investigations with different types of long-chain guest molecules, it was concluded that complexes with two $\alpha$-CD molecules and one guest molecule can be formed in addition to the $1: 1$ complexes.
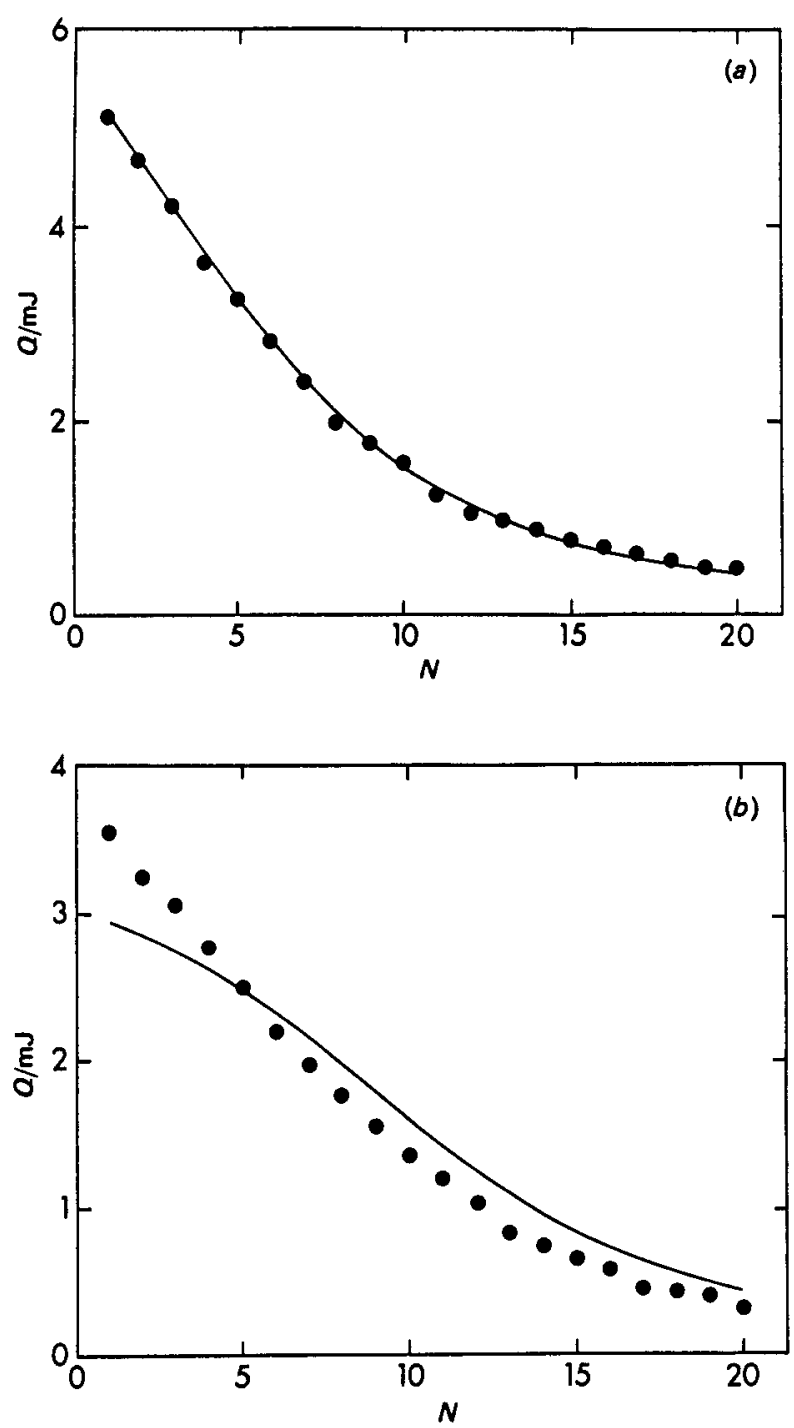

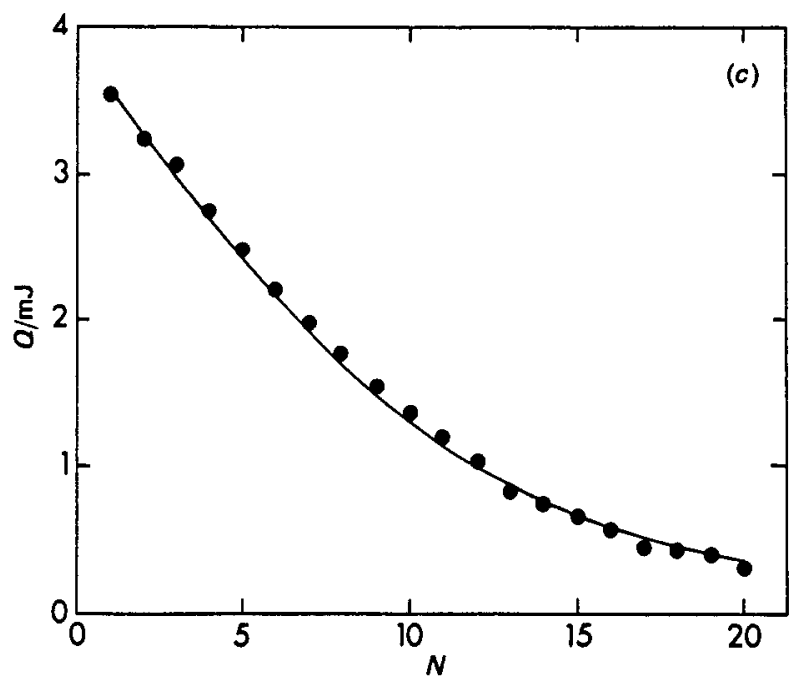

Fig. 1 Heat evolution per injection, $Q$, plotted against injection number, $N$. Experimentally obtained values. - Fitted lines for
(a) hexan-1-ol
(b) heptan-1-ol assuming a one-step binding model
(c) heptan-1-ol assuming a two-step binding model 
Experiments were conducted at three temperatures, 15,25 and $35^{\circ} \mathrm{C}$. In Figs $2-5$ the derived thermodynamic results, $\Delta G_{\mathrm{m}}^{\circ}, \Delta H_{\mathrm{m}}^{\circ}, \Delta S_{\mathrm{m}}^{\circ}$, and $\Delta C_{\mathrm{p}, \mathrm{m}}^{\circ}$ are plotted versus the number of carbon atoms in the alkanol molecules, $n_{\mathrm{c}}$.

For a discussion of the obtained thermodynamic values, the very simple symbols used in eqn (24) can be deceptive. A somewhat more realistic picture can be formulated, eqn (25), if we look upon the binding process as the transfer of a fully solvated (hydrated) guest molecule to the binding site (presumably the cavity of the $\alpha-C D$ molecule). The $\alpha-C D$ molecule is also solvated and we may assume that some of the solvent (water) molecules originally present in the cavity will be forced out by the guest molecule.

$$
(\mathrm{ROH})_{\mathrm{aq}}+\left(\alpha-\mathrm{CD} \cdot \mathrm{n} \mathrm{H}_{2} \mathrm{O}\right)_{\mathrm{aq}}=\left(\alpha-\mathrm{CD} \cdot(\mathrm{n}-\mathrm{x}) \mathrm{H}_{2} \mathrm{O} \cdot \mathrm{ROH}\right)_{\mathrm{aq}}+\mathrm{x}\left(\mathrm{H}_{2} \mathrm{O}\right)_{\mathrm{aq}}
$$

The binding (or the transfer) process then hypothetically can be thought of as a multi-step reaction: (i) dehydration of part of ROH; (ii) solvation of the hydrocarbon chain by the (partially hydrophobic) medium in the cavity of $\alpha-C D$ and release of some (x) water molecules; (iii) possibly some conformational change of the $\alpha-C D$ molecule; (iv) transformation of water molecules released from the cavity to form bulk water.
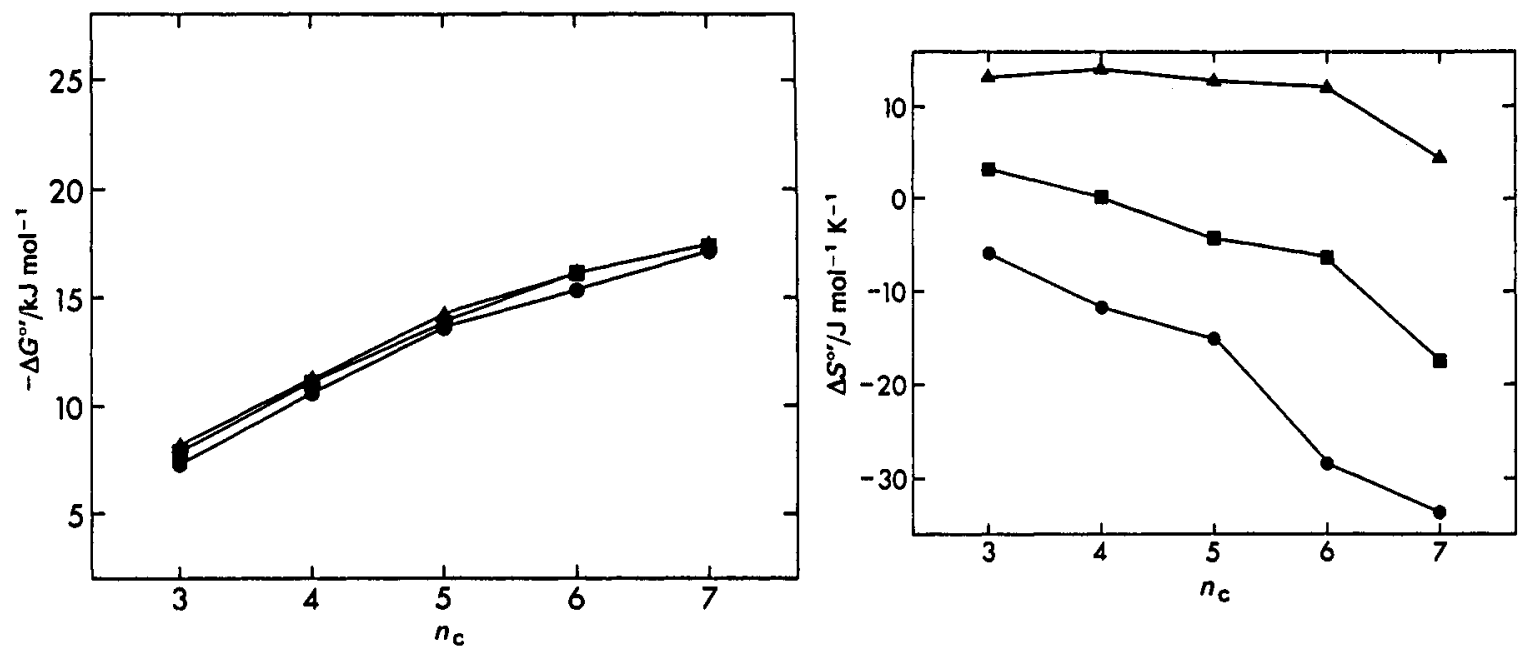

Fig. $2 \Delta G^{\circ \prime}$ for the binding of alkan-1-ols to $\alpha$-cyclodextrin against Fig. $4 \Delta S^{\prime}$ for the binding of alkan-1-ols to $\alpha$-cyclodextrin the number of carbon atoms, $n_{\mathrm{c}} . \Delta, 288.15 \mathrm{~K} ; \mathrm{Z}, 298.15 \mathrm{~K} ; 0$, against the number of carbon atoms, $n_{\mathrm{c}} . \Delta, 288.15 \mathrm{~K}$; $308.15 \mathrm{~K}$

口, $298.15 \mathrm{~K} ; 0,308.15 \mathrm{~K}$
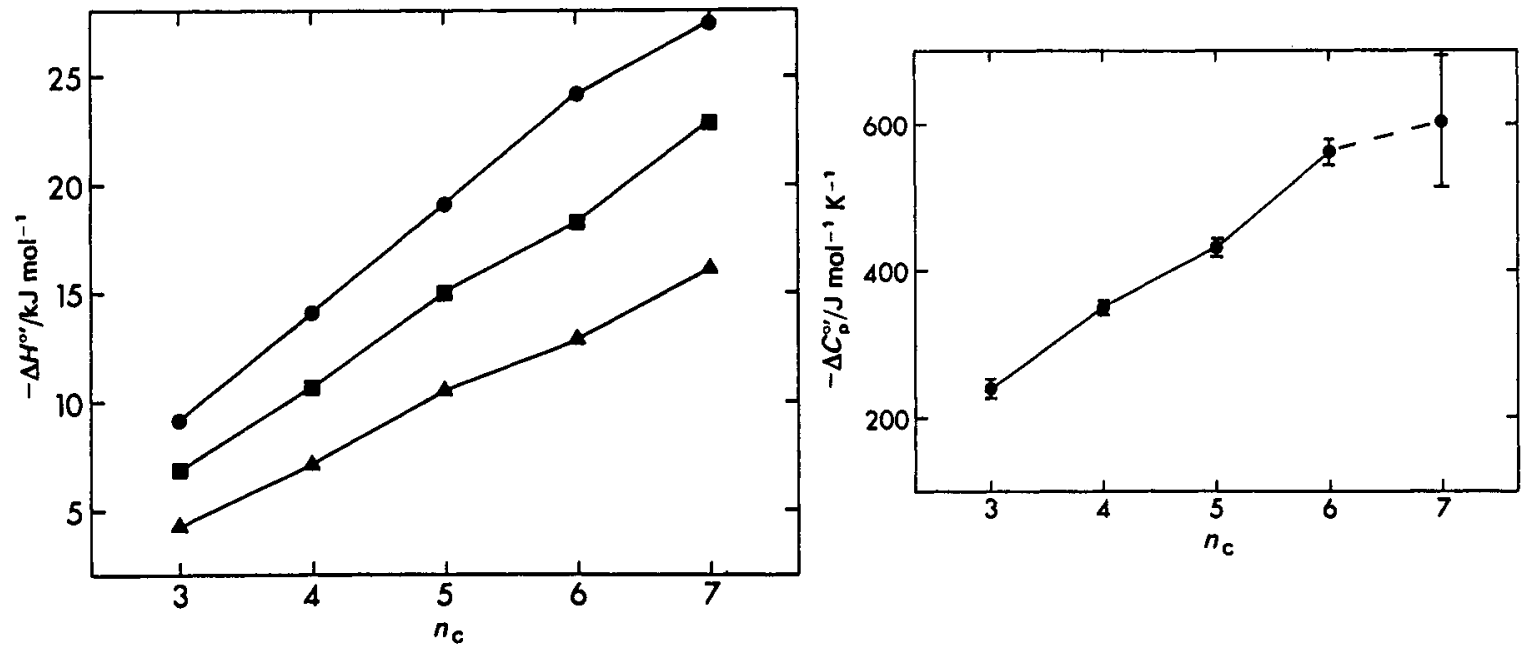

Fig. $3 \Delta H^{\circ \prime}$ for the binding of alkan-1-ols to $\alpha$-cyclodextrin against Fig. $5 \Delta C_{p}^{o r}$ for the binding of alkan-1-ols to $\alpha$-cyclodextrin the number of carbon atoms, $n_{\mathrm{c}} . \Delta, 288.15 \mathrm{~K} ; \mathrm{C}, 298.15 \mathrm{~K} ; \boldsymbol{O}$, against the number of carbon atoms, $n_{\mathrm{c}}$ $308.15 \mathrm{~K}$ 
It is estimated that alkyl chains with a maximum of five or six carbon atoms can be accomodated in the cavity. One can thus possibly expect that at least for heptan-1-ol, one methylene group will remain solvated by the bulk water and not take part in the process. Taken together, contributions (i) and (ii), usually called 'hydrophobic interaction', often are assumed to be the main driving force for the transfer of an alkyl group into a non-aqueous environment. However, at this stage we cannot, with any confidence, make realistic quantitative assignments of the different contributions (i) - (iv). A discussion of the results therefore must be mainly on a qualitative level.

Inspection of Figures $2-4$ shows that the $\Delta G^{\circ}$-values are essentially temperature independent within the temperature range investigated but that $\Delta H^{\circ}$ - and $\Delta S^{\circ}$-values have large temperature dependence. Such results demonstrate the importance of conducting these kind of experiments at several temperatures otherwise the thermodynamic picture might appear to be far too simple. It seems surprising that many workers in this field dare to analyze data from experiments conducted only at one temperature! A wide experimental temperature range is also important from the point of view that such measurements will lead to $\Delta C_{p}^{\circ}$-values eqn (2), which have proved to be particularly important for the transfer of hydrophobic groups between an aqueous solution and a non-aqueous phase, $c f$ below.

From Fig 2 is seen that the initially linear plot of $-\Delta \mathrm{G}^{\circ}$ against $n_{\mathrm{c}}$ levels off at $n_{\mathrm{c}}=5$, which agrees with the depth of the cavity through the $\alpha-\mathrm{CD}$ molecule. The $\mathrm{CH}_{2}$-increment of the linear part is about $3 \mathrm{~kJ} \cdot \mathrm{mol}^{-1}$, which is a typical value for the transfer of a $\mathrm{CH}_{2}$-group from water to a liquid organic phase (33). The enthalpy changes, Fig 3, also increase linearly but no levelling-off effect is observed. The $\mathrm{CH}_{2}-$ increment is about $4 \mathrm{~kJ} \cdot \mathrm{mol}^{-1}$, which is high compared to $\mathrm{CH}_{2}$-increment values derived from calorimetric dissolution experiments on many series of organic liquids, typically $\leq 1.5 \mathrm{~kJ} \cdot \mathrm{mol}^{-1}(33)$.

For the whole temperature range investigated, the entropy change will increase with increasing chain length, Fig 4. This is in line with what is expected for a hydrophobic dehydration process. However, that effect is not expected to lead to the more pronounced negative $\mathrm{CH}_{2}$-increment observed for $n_{\mathrm{c}}>5$ or 6 . As for many other ligand binding processes, we can observe a significant enthalpy - entropy compensation (33) for this system, both with respect to temperature and structure, Figs $2-4$.

The partial molar heat capacity for a hydrophobic compound (or corresponding contribution from a hydrophobic group) is much larger for aqueous solutions than for solutes in organic solvents (for example, a pure liquid organic compound). We can thus expect that the transfer of an alkane chain from aqueous solution to the medium provided by the cavity in $\alpha-C D$ will be accompanied by a large decrease in heat capacity for the system. This is in qualitative agreement with the experimental results, Fig. 5. However, these results show a $\mathrm{CH}_{2}$-increment of about $-100 \mathrm{~J} \cdot \mathrm{K}^{-1} \mathrm{~mol}^{-1}$ whereas the value expected for the assumed transfer process is significantly less negative, about -50 to $-60 \mathrm{~J} \cdot \mathrm{K}^{-1} \mathrm{~mol}^{-1}(33)$.

In summary, our analysis is consistent with the view that hydrophobic interactions are important in the formation of complexes between $\mathrm{ROH}$ and $\alpha-\mathrm{CD}$ but the results clearly indicate that other effects also are important.

\section{Conclusions}

Microcalorimetry is currently applied in different types of experiments involving macrocyclic compounds, most importantly in studies of ligand binding processes by use of batch titration or flow mixing microcalorimetry. Such measurements frequently will lead not only to a value for the overall enthalpy change for the process but also to information about the binding stoichiometry and to values for the equilibrium constant(s) and corresponding molar changes of Gibbs energy, enthalpy and entropy. In many cases the equilibrium constant is of a direct practical importance, for example in applied areas such as analytical and pharmaceutical chemistry. However, the influence of temperature and structural parameters is often poorly reflected in a series of $\Delta G^{\circ}$-values compared to corresponding values for $\Delta H^{\circ}$ and $\Delta S^{\circ}, c f$, for example, $(33,34)$. Unfortunately, at the present time discussions of such effects must largerly be kept on an empirical - qualitative level. Solvation of the reaction components will often give very large contributions to the values for $\Delta H^{\circ}, \Delta S^{\circ}$ and $\Delta C_{\mathrm{p}}^{\circ}$ of a ligand binding process. Detailed studies of the thermodynamic parameters for the transfer of reaction components, and simple model compounds, between different media should therefore be encouraged. As was stressed earlier, it is of outmost importance to conduct thermodynamic measurements for ligand binding processes, and for the reaction components, at different temperatures, in particular when processes are conducted in aqueous solution. There are good reasons to have $25^{\circ} \mathrm{C}$ as a reference temperature. However, this does not imply that our thermodynamic characterization of ligand binding processes should be restricted to that temperature! 


\section{Acknowledgements}

This work has been supported by the Swedish Natural Science Research Council. Figures 1 - 5 are reproduced from reference (33), with permission.

\section{References}

1. A.F. Danil de Namor, Ind. J. Technol., 30, 593 (1992)

2. L.-E. Briggner and I. Wadsö, J. Chem. Thermodynamics, 22, 1067 (1990)

3. Y. Inoue, T.Hakushi, Y. Liu, L.-H. Tong, B.-I. Shen and D.-S. Jin, J. Am. Chem. Soc., 115, 475, (1993)

4. I. Gómez-Orellana, D. Hallén and M. Stödeman, J. Soc. Faraday Trans., 90, 3397, (1994)

5. M.V. Rekharsky, F.P. Schwarz, Y.B. Tewari and R.N. Goldberg, J. Phys. Chem., 98, 10282 (1994)

6. Y. Liu, T.-B. Lu, M.-Y. Tan, T. Hakushi and Y. Inue, J. Phys. Chem., 97, 4548 (1993)

7. H.-J. Buschmann, Inorg. Chim. Acta, 195, 51 (1992)

8. A.F. Danil de Namor, M.C. Cabaleiro, B.M. Vuano, M. Salomon, O.I. Pieroni, D.A.P. Tanaka, C.Y. Ng, M.A.L. Tanco, N.M. Rodriguez, J.D.C. Garcia and A.R. Casal, Pure Appl. Chem., 66, 435 (1994)

9. I. Wadsö in Thermal and Energetic Studies of Cellular Biological Systems (A.M. James, ed), pp. 34 67, Wright, Bristol (1987)

10. I. Wadsö in Solution Calorimetry, Experimental Thermodynamics, Volume IV (IUPAC Commission on Thermodynamics) (K.N. Marsh and P.A.G. O'Hare, eds) pp. 267 - 301, Blaxkwell Sci. Publ., London (1994)

11. P. Bäckman, M. Bastos, D. Hallén, P. Lönnbro and I. Wadsö, J. Biochem. Biophys. Methods, 28, 85 (1994)

12. S.L Randzio and J. Suurkuusk in Biological Microcalorimetry (A.E. Beezer, ed) pp. 311 - 341, Academic Press, London (1980)

13. M. Eftink and R. Biltonen in Biological Microcalorimetry (A.E. Beezer, ed) pp. $343-412$, Academic Press, London (1980)

14. E. Freire, O.L. Mayorga and M. Straume, Anal. Chem., 62, 950 A (1990)

15. T. Wiseman, S. Williston, J. F. Brandts and L.-N. Lin, Anal. Biochem., 179, 131 (1989)

16. J.L. Oscarson, R. Izatt, J.O. Hill and P.R. Brown in Solution Calorimetry, Experimental Thermodynamics, Volume IV (IUPAC Commission on Thermodynamics) (K.N. Marsh and P.A.G. O'Hare, eds) pp. 267 - 301, Blackwell Sci. Publ., London (1994)

17. M. Yamamoto and H. Aki, J. Biochem. Biophys. Methods, 16, 271 (1988)

18. R. Karlsson and L. Kullberg, Chem. Scripta, 9, 54 (1976)

19. M. Yamamoto and H. Aki, Thermochim. Acta 193, 287 (1991)

20. D. Hallén, Pure Appl. Chem., 7, 1527 (1993)

21. Bevington, Data Reduction and Error Analysis for the Physical Sciences, Mc Graw-Hill inc., New York (1969)

22. E.J. King, Acid Base Equilibria, pp. 184 - 217, Pergamon Press, Oxford (1965)

23. B.W. Sigurskjold, C.R. Berland and B. Svensson, Biochem., 33, 10191 (1994)

24. A.F. Danil de Namor, R. Traboulssi and D.F.V. Lewis, J. Am. Chem. Soc., 112, 8442 (1990)

25. D. Hallén and I. Wadsö, Pure Appl. Chem., 61(2), 123 (1989)

26. D. Hallén, S.-O. Nilsson and I. Wadsö, J. Chem. Thermodynamics, 21, 529 (1989)

27. S.F. Dec and S.J. Gill, Rev. Sci. Instrum., 55, 765 (1984)

28. D. Hallén and I. Wadsö, J. Chem. Thermodynamics, 21, 519 (1989)

29. S.-O. Nilsson and I. Wadsö, J. Chem. Thermodynamics, 18, 1125 (1986)

30. K.P. Murphy and S.J. Gill, Thermochim. Acta, 139, 279 (1989)

31. D. Hallén, E. Qvarnström and I. Wadsö, To be published.

32. J. Suurkuusk and I. Wadsö, Chem. Scripta, 20, 155 (1982)

33. D. Hallén, A. Schön, I. Shehatta and I. Wadsö, J. Chem. Soc. Faraday Trans., 88, 2859 (1992)

34. M. Bastos, L.-E. Briggner, I. Shehatta and I. Wadsö, J. Chem. Thermodynamics, 22, 1181 (1990) 